\title{
Female athletes and health
}

\author{
Marzena Malara, Grażyna Lutosławska \\ Department of Biochemistry and Biology, Józef Piłsudski University of Physical Education, Warsaw, Poland
}

\section{Summary}

It is well documented that regular physical activity has a beneficial effect on human health by affecting the metabolic processes that are of fundamental importance in the body's functions, such as insulin sensitivity and glucose disposal, as well as lipid and lipoprotein turnover. On the other hand, there is a wealth of studies which indicate that strenuous, regular physical activity, such as that performed by high performance athletes, may be detrimental for the athletes' health especially in women. This review focuses on the factors that contribute to health problems in female athletes, named the female athlete triad, which includes excessive dieting, menstrual dysfunctions (anovulatory menstrual cycles, oligomenorrhea, amenorrhea) and a low bone mineral density (BMD). As a result of these factors, women who participate in sports, especially those focused on leanness, need special attention and education from health professionals, coaches and the athletes themselves to prevent the detrimental effects of an inadequate energy supply against high energy demands.

\section{Key words: Female athlete - Menstrual dysfunction - Energy deficit - Health risk}

\section{Introduction}

It is well documented that, irrespectively of gender, regular physical activity provides benefits for human health by affecting the metabolic processes that are of fundamental importance in the body's functions, such as insulin sensitivity and glucose disposal, as well as lipid and lipoprotein turnover $[22,23]$. In consequence, the concept of exercise as a "polypill" against several health problems has recently received much attention [16]. On the other hand, there is also data which suggests that regular strenuous physical activity, such as that performed in high performance sport, may be detrimental for the athlete's health by inducing cardiac remodelling, arterial endofibrosis, impaired vascular compliance, oxidative stress and impaired immune functions [ $8,20,38,45,52]$. Additionally, there is numerous data that clearly indicates female athletes are at a greater risk of adverse health effects from sport-related physical activity than their male counterparts. It is also well documented that female athletes are at the greatest risk of a poor iron status due to blood loss from menses, but also due to a low density of dietary iron $[1,27]$.

\section{Health risks in female athletes - the female athlete triad}

At present, it is commonly accepted that poor dietary habits in female athletes also bring about other health disturbances, such as anovulatory menstrual cycles, oligomenorrhea, amenorrhea and a decreased bone mineral density (BMD) [5, 58]. According to Klungland-Torstveit et al. [26] three symptoms (disordered eating, amenorrhea and a lowered BMD), named the female athlete triad, can be observed in $4.3 \%$ of all female athletes. However, the frequency of eating disorders and menstrual dysfunctions is much higher, and ranges from 5.4 to $26.9 \%$. In addition, triad symptoms were identified in high school athletes aged $13-18$ years old, where $5.9 \%$ of the participants met two of the triad components and $1.2 \%$ experienced all three components of the triad [43]. Moreover, it was noted that in amenorrheic female runners, the plasma total cholesterol and LDL-cholesterol levels were higher than in their regularly menstruating counterparts $[17,25,28]$. Rickelund et al. [50] showed that amenorrhea in female athletes is associated with an unfavourable lipoprotein profile, and an endothelial dysfunction expressed as a decreased flow mediated dilatation (FMD). These findings may be of importance, since Solomon et al. [54] in a cohort study demonstrated that a menstrual cycle irregularity in females aged 20-35 years can increase the future risk of cardiovascular disease.

Moreover, Lloyd et al. [30] revealed that in oligomenorrheic female athletes engaged in track and field, field hockey and basketball, the bone mineral density (BMD) was significantly lower than in eumenorrheic athletes. The association between a disturbed ovarian hormone 
secretion and a decreased BMD was confirmed in female runners, dancers and football players, but also in swimmers and volleyball players $[9,42,56,59]$. However, it is worth noting that the studies which enabled a diagnosis of the female athlete triad started much earlier, and concerned the disturbances in sex hormone secretions in women who engaged in a strenuous physical activity.

\section{History of exercise - the female athlete triad connection}

In the early $1980 \mathrm{~s}$, it was demonstrated that 16 of the 48 women enrolled in marathon training were characterised by a monophasic body temperature [46]. Additionally, among 32 women with biphasic BBT only 16 had a normal luteal phase length (mean $11.1 \pm 1.2$ days), while the other 16 women had biphasic cycles that were characterised by a short luteal phase (mean $6.4 \pm 1.8$ days). Moreover, in the subjects with a monophasic BBT or a short luteal phase, the daily running distance was longer than in the participants with normal menstrual cycles (about 10 vs. 8 miles/day). The above data clearly suggests that regular training adversely affects the ovarian hormone secretions and that this effect is intensified with an increased training load. The detrimental effect of strenuous and regular physical activity on the circulating female sex hormones has been supported by many studies [4, 6, 14]. Moreover, a delayed menarche or even amenorrhea was reported in adolescent ballet dancers [19]. Further studies have also indicated disturbed luteinising hormone (LH) and folliclestimulated hormone (FSH) secretions in females who are engaged in regular training of a low intensity $[3,12]$.

At the time of these studies, some authors hypothesised that rigorous exercise should be recognised as a stressor for increasing $\mathrm{ACTH}$ and cortisol secretions and the plasma levels, which in turn has a potential to depress the gonadotrophin-releasing hormone $(\mathrm{GnRH})$ pulse generation [32]. However, the hormonal disturbances in female athletes were not limited to sex hormone, adrenal hormone and gonadotrophin secretions. In amenorrheic, the total circulating triiodothyronine $\left(\mathrm{T}_{3}\right)$ and leptin was depressed, suggesting a hypometabolic state [13]. This assumption has been supported by further studies which indicated that the resting energy expenditure per kilogram of fat free mass in exercising women with anovulatory menstrual cycles was lower than in ovulating women, but in amenorrheic participants it was even lower than in their non-ovulating counterparts [11].

Thus, it seemed that menstrual dysfunctions shifted the female hormonal profile in a direction which promoted energy conservation. Taking into account that, in humans, energy is conserved mostly in the adipose tissue, these findings enabled a return to the old hypothesis concerning fat levels as a determinant of the menarche and normal menstrual cycle [18]. On the other hand, some data suggested that no relationship existed between body fat and reproduction, since no differences in adiposity were noted between eumenorrheic and amenorrheic female runners [32, 51]. However, a close association was shown between a disturbed sex hormonal profile and low energy availability (energy intake reduced by energy expenditure) in women who engaged in strenuous physical activity [31, 34, 63]. Interestingly, deteriorations in the LH and FSH secretions similar to those observed in female athletes were observed in sedentary women with eating disorders, such as bulimia nervosa $[29,49]$. Thus, it was postulated that hormonal disturbances in female athletes are the body's response to an inadequate energy intake vs. a high energy expenditure.

\section{Energy availability in female athletes}

Numerous data has demonstrated that the energy intake in active females is inadequate, taking into account their increased energy expenditure. However, this energy inadequacy is most common in sports which are focused on leanness (e.g. gymnastics, distance running and figure skating) but also occurs in other sports such as soccer and surfing [15, 41, 44, 64]. Sudi et al. [55] noted that in some female athletes, anorexia athletica was even observed, with a markedly restricted calorie intake and over-exercising to achieve or maintain a low body and fat mass. According to Manore [37], most female athletes require at least 2300-2500 kcal/day to maintain their body weight. In the case of endurance sports (marathon, triathlon) their daily requirements may be as high as $4000 \mathrm{kcal} / \mathrm{day}$. On the other hand, Loucks et al. [33] proved that an energy availability (defined as the energy intake minus the energy expenditure) of $30 \mathrm{kcal} / \mathrm{kg} \mathrm{LBM} /$ day is a threshold value below which the reproductive function is depressed due to disturbances in the LH pulsatility and amplitude. Moreover, Williams et al. [62] demonstrated that the frequency of menstrual disturbances is markedly affected by the magnitude of the daily energy deficit, and is significantly greater for a $42 \%$ than for an $8 \%$ energy deficiency. Since the time of these earlier studies until now, intense research has focused on analysing the dietary habits of female athletes and their energy availability [39, 47, 48, 53, 61].

In consequence, to prevent the adverse effects of energy shortages, De Souza et al. [10] have recommended developing psychometric indices for evaluating the drive for thinness as a proxy indicator of energy deficiency in exercising women, to prevent the development of dietary disorders. Recently, Melin et al. [39] proposed the LEAF Questionnaire (Low Energy Availability in Female Questionnaire), which is composed of questions regarding dietary habits and health problems, including the reproductive functions of female athletes. This procedure seems to be of importance, since it has been found that dietary interventions have the potential to restore menses in female athletes $[2,7,21,36]$. 
Furthermore, it is worth noting that despite many years of studies concerning the female athlete triad, and clear procedures to prevent its adverse effects, recent data indicates that a similar phenomenon can be observed in male sportsmen who are engaged in disciplines that emphasise a lean body composition, accompanied by the well-known adverse effects including false dietary habits, hypogondotrophic hypogonadism and a low bone mineral density $[24,57]$. Thus, both coaches and sport medicine health professionals need to be especially concerned about the dietary habits of athletes to protect them from adverse health effects and a decrease in their performance.

\section{References}

1. Alaunyte I., V. Stojceska, A.S. Plunkett (2015) Iron and female athlete: a review of dietary treatment methods for improving iron status and exercise performance. J. Int. Soc. Sports Nutr., 12: 38. DOI: 10.1186/s1270-0150099-2.

2. Arends J.C., M.Y. Cheung, M.T. Barrack, A. Nattiv (2012) Restoration of menses with non-pharmacologic therapy in college athletes with menstrual disturbances: a 5-year retrospective study. Int. J. Sport Nutr. Exerc. Metab., 22: 98-108.

3. Beitins I.Z., J.W McArthur., B.A. Turnbull, G.S. Skrinar, B.A. Bullen (1991) Exercise induces two types of human luteal dysfunction: confirmation by urinary free progesterone. J. Clin. Endocrinol. Metab., 72: 1350-1358.

4. Broocks A., K.M. Pirke, U. Schweiger, R.J. Tuschl, R.G. Laesser, T. Strowitzki (1990) Cyclic ovarian function in recreational athletes. J. Appl. Physiol., 68: 2083-2086.

5. Brunet M. (2005) Female athlete triad. Clin. Sports, 24: 623-636. DOI: 10.1016/j.csm.2005.03.009.

6. Bullen B.A., G.S. Skrinar, I.Z. Beitins, B. Van Mehring, A. Turnbull, J.W. McArthur (1985) Induction of menstrual disorders by strenuous exercise in untrained women. N. Eng. J Med., 312: 1349-1353.

7. Ciadell-Kam L., C.P. Guebels, G.F. Maddalozzo, M.M. Manore (2014) Dietary intervention restored menses in female athletes with exercise - associated menstrual dysfunction with limited impact on bone and muscle health. Nutrients, 6: 3018-3039. DOI: 10.3390/ nu6083018.

8. Cioni G., A. Berni, G.F. Gensini, R. Abbate, M. Boddi (2015) Impaired femoral vascular compliance and endothelial dysfunction in 30 healthy male soccer players: competitive sports and local detrimental effects. Sport Health, 7: 335-340. DOI: 10.1177/19417381115577931.

9. Cobb K.L., L.K. Bachrach, G. Greendale, R. Marcus, R.M. Neer, J. Nieves (2003) Disordered eating, menstrual irregularity, and bone mineral density in female runners. Med. Sci. Sports Exerc., 35: 711-719.

10. De Souza M.J., R. Hontscharuk, M. Olmsted, G. Kerr, N.I. Williams (2007) Drive for thinness score is a proxy indicator of energy deficiency in exercising women. $A p$ petite, 48: 359-367.

11. De Souza M.J., D.K. Lee, J.L. Van Heest, J.L. Scheid, S.L. West, N.I. Williams (2007) Severity of energy related menstrual disturbances increases in proportion to indices of energy conservation in exercising women. Fertil. Steril., 88: 971-975.

12. De Souza M.J., B.E. Miller, A.B. Loucks, A.A. Luciano, L.S. Pescatello, C.G. Campbell (1998) High frequency of luteal phase deficiency and anovulation in recreational women runners: blunted elevation in follicle-stimulating hormone observed during luteal-follicular transition. J. Clin. Endocrinol. Metab., 83: 4220-4232.

13. De Souza M.J., J. Van Heest, L.M. Demers, B.L. Lasley (2003) Luteal phase deficiency in recreational runners: evidence for hypometabolic state. J. Clin. Endocrinol. Metab., 88: 337-346.

14. Ellison P.T., C. Lager (1986) Moderate recreational running is associated with lowered progesterone profiles in women. Am. J. Obstet. Gynecol., 154: 1000-1003.

15. Felder J.M., L.M. Burke, B.J. Lowdon, D. CameronSmith, G.R. Collier (1998) Nutritional practices of elite female surfers during training and competition. Int. J. Sport. Nutr. Metab., 8: 36-48.

16. Fiuza-Luces C., N. Garatechea, N.A. Bergier, A. Lucia (2013) Exercie is the real polypill. Physiology, 28, 330358. DOI: 10.1152/physiol.00019.2013.

17. Friday K.E., B.L. Drinkwater, B. Bruemmer, C. Chestnut, A. Chait (1993) Elevated plasma low-density and highdensity lipoprotein cholesterol levels in amehorrheic athletes: effects of endogenous hormone status and nutrient intake. J. Clin. Endocrinol. Metab., 7: 1605-1609.

18. Frisch R.E., J.W. McArthur (1974) Menstrual cycles: fatness as a determinant of minimum weight for height necessary for their maintenance or onset. Science, 185: 949-951.

19. Frisch R.E., G. Wyshak, L. Vincent (1989) Delayed menarche and amenorrhea in ballet dancers. N. Eng. J. Med., 303: 17-19.

20. Gleeson M., D.B. Pyne (2016) Respiratory inflammation and infections in high-performance athletes. Immunol. Cell Biol., 94: 124-131. DOI: 10.1038/icb.2015.100.

21. Guebels C.P., L.C. Kam, G.F. Maddalozzo, M.M. Manore (2014) Active women before/after an intervention designed to restore menstrual function: resting metabolic rat and comparison of four methods to quantify energy expenditure and energy availability. Int. J. Sport. Nutr. Exerc. Metab., 24, 37-46. DOI: og/10.1123/ijsnem.20120165 . 
22. Hawley J.A., M. Hargreaves, M.J. Joyner, J.R. Zierath (2014) Integrative biology of exercise. Cell, 159: 738-749. DOI: .org/10.1016/j.cell.2014.10.10.029.

23. Heinonen I., K.K. Kalliokoski, J.C. Hanukainen, D.J. Duncker, P. Nuutila, J. Knuuti (2014) Organ-specific physiological responses to acute physical exercise and long-term training in humans. Physiology, 29: 421-436. DOI:10.1152/physiol.00067.2013.

24. Joy E., A. Kussman, A. Nattiv (2016) update on eating disorders in athletes: a comprehensive narrative review with a focus on clinical assessment and management. Br. J. Sports Med., 50: 154-162. DOI: 10.1136/bjsports2015-095735.

25. Kaiserauer S., A.C. Snyder, M. Sleeper, J. Zierath (1989) Nutritional, physiological, and menstrual status of distance runners. Med. Sci Sports Exec., 21: 120-125.

26. Klungland-Torstveit M., J. Sundgot-Borgen (2005) The female athlete triad exists in both elite athletes and controls. Med. Sci. Sports Exerc., 37: 1449-1459.

27. Koehler K., H. Braun, S. Achtzen, U. Hilderbrandt, H.G. Predel, J. Mesyer, W. Schänzer (2012) Iron status in elite young athletes: gender-dependent influences of diet and exercise. Eur. J. Appl. Physiol., 112: 513-523.

28. Lamon-Fava S., E.C. Fisher, M.E. Nelson, W.J. Evans, J.S. Millar, J.M. Ordovas, E.J. Schaefer (1989) Effect of exercise and menstrual cycle status on plasma lipids, low density lipoprotein particle size, and apolipoproteins. J. Clin. Endocrinol. Metab., 68: 17-21.

29. Laughlin G.A., C.E. Dominguez, S.S. Yen (1998) Nutritional and endocrine-metabolic aberrations in women with functional hypothalamic amenorrhea. J. Clin. Endocrinol. Metab., 83: 25-32.

30. Lloyd T., J.R. Buchanan, S. Bitzer, C.J. Waldman, C. Myers, B.G. Ford (1987) Interrelationships of diet, athletic activity, menstrual status, and bone density in collegiate women. Am. J. Clin. Nutr., 46: 681-684.

31. Loucks A.B., E.M. Heath (1994) Dietary restrictions reduces luteinizing hormone ( $\mathrm{LH})$ pulse frequency during waking hours and increases LH pulse amplitude during sleep in young menstruating women. J. Clin. Endocrinol. Metab., 78: 910-915.

32. Loucks A.B., S.M. Horvath (1984) Exercise-induced stress responses of amenorrheic and eumenorrheic runners. J. Clin. Endocrinol. Metab., 59: 1109-1120.

33. Loucks A.B., J.R. Thuma (2003) Luteinizing hormone pulsatility is disrupted at a threshold of energy availability in regularly menstruating women. J. Clin. Endocrinol. Metab., 88: 297-311.

34. Loucks A.B., M. Verdun, E.M. Heath (1998) Low energy availability, not stress of exercise, alters LH pulsatility in exercising women. J. Appl. Physiol., 84: 37-46.

35. Loucks A.B. (1990) Effects of exercise training on the menstrual cycle: existence and mechanisms. Med. Sci. Sports Exerc., 22: 275-280.
36. Łagowska K., K. Kapzuk, Z. Friebe, J. Bajerska (2014) Effects of dietary intervention in young female athletes with menstrual disorders. J. Int. So. Sport Nutr., 11: 21. http://www.jissn.com.content/11/1/21.

37. Manore M.M. (2002) Dietary recommendations and athletic menstrual dysfunction. Sports Med., 32: 887-901.

38. Marin D.P., A.P. Bolin, T.R. Campoio, B.A. Guerra, R. Otton (2013) Oxidative stress and antioxidant status response of handball athletes: implications for sport training monitoring. Int. Immunopharm., 17: 462-470. DOI: org/j.intimp.2013.07009.

39. Melin A., A.B. Tornberg, S. Skouby, J. Faber, C. Ritz, A. Sjödin, J. Sundgot-Borgen (2014) The LEAF questionnaire: a screening tool for the identification of female athletes at risk for the female athlete triad. Br. J. Sports Med., 48: 540-545. DOI: 10.1136/bjsports-2013-093240.

40. Melin A., A.B. Tornberg, S. Skouby, S.S. Möller, J. Faber, J.J. Sidelmann, M. Aziz, A. Sjödin (2015) Energy availability and female athlete triad in elite endurance athletes. Scand. J. Med. Sci. Sports, 25: 610-622. DOI: 10.1111/ sms. 12261.

41. Mullinix M.C., S.S. Jonnalagadda, C.A. Rosenbloom, W.R. Thompson, J.R. Kicklighter (2003) Dietary intake of female U.S. soccer players. Nutr. Res., 23: 585-593.

42. Nichols J.F, M.J. Rauh, M.T. Barrack, H.S. Barkai (2007) Bone mineral density in female high school athletes: interactions of menstrual function and type of mechanical loading. Bone, 41: 371-377.

43. Nichols J.F., M.J. Rauh, M.J. Lawson, J. Ming, H.S. Barkai (2006) Prevalence of the female athlete triad syndrome among high school athletes. Arch. Pediatr. Adolesc. Med., 160: 137-142.

44. Nova E., A. Montero, S. López-Varela, A. Marcos (2001) Are elite gymnasts really malnourished? Evaluation of diet, anthropometry and immunocompetence. Nutr. Res., 21: $15-29$.

45. Peach G., G. Schep, R. Palfreemen, J.D. Beard, M.M. Thompson, R.J. Hinchliff (2012) Endofibrosis and kinking of the ilac arterie in athletes: A systemic review. Eur. J. Vasc. Endovasc. Surg., 43: 208-217. DOI: 10.1016/j.ejvs.2011.11.019.

46. Prior J.C., K. Cameron, B.H. Yuen, J. Thomas (1982) Menstrual cycle changes with marathon training: anovulation and short luteal phase. Can. J. Appl. Sport Sci., 7: 173-177.

47. Reed J.L., J.L. Bowell, B.R. Hill, B.A. Williams, M.J. De Souza, N.L. Williams (2011) Exercising women with menstrual disturbances consume low energy dense foods and beverages. Appl. Physiol. Nutr. Metab., 36: 382-394. DOI: 10.11349/H11-030.

48. Reed J.L., M.J. De Souza, J.M. Kindler, N.I. Williams (2014) Nutritional practices associated with low energy availability in Division I female soccer players. J. Sports Sci., 32: 1499-1509. 
49. Resch M., G. Sznedel, P. Haasz (2004) Eating disorders from gynecologic and endocrinologic view: hormonal changes Fertil. Steril., 81: 1151-1153.

50. Rickenlund A., M.J. Eriksson, K. Schenk-Gustafsson, A.L. Hirschberg (2005) Amenorrhea in female athlete is associated with endothelial dysfunction and unfavorable lipid profile. J. Clin. Endocrinol. Metab., 90: 1354-1359.

51. Sanborn C.F., B.H. Albrecht, W.W. Wagner (1987) Amenorrhea: lack of associations with body fat. Med. Sci. Sports Exerc., 19: 207-222.

52. Scharhag J., H. Löllgen, W. Kinderman (2013) Competitive sports and the heart: benefit or risk? Dtsch. Arztebl. Int., 110: 14-24.

53. Silva M.R., T. Paiva (2015) Low energy availability and low body fat of female gymnasts before an international competition. Eur. J. Sports. Sci., 15: 591 - 599.

54. Solomon C.G., F.B. Hu, A. Dunaif, J.E. Rich-Edwards, M.J. Stampfer, W.C. Willet (2002) Menstrual cycle irregularities and risk of future cardiovascular disease. J. Clin. Endocrinol. Metab., 87: 2013-2017.

55. Sudi K., K. Öttl, D. Payerl, P. Baumgartl, K. Tauschmann, W. Müller (2004) Anorexia athletica. Nutrition, 20: 657-661.

56. Sundgot-Borgen J., M. Klungland-Torsveit (2007) The female football players, disordered eating, menstrual function and bone health. Br. J. Sports Med., 41: 168-172.

57. Tenforde A.S., M.T. Barrack, A. Nattiv, M. Fredericson (2016) Parallels with the female athlete triad in male athletes. Sports Med., 46: 171-182. DOI: 10.1007/s40279015-0411-y.

58. Thein-Nissenbaum J. (2013) Long-term consequences of the female athlete triad. Maturitas, 75: 107-112. DOI: org/10.1018/j.maturitas.2013.02.010.
59. To W.W., M.W. Wong, I.Y. Lam (2005) Bone mineral density differences between adolescent dancers and nonexercising adolescent females. J. Pediatr. Adolesc. Gynecol., 18: 337-342.

60. Torstveit M.K., J. Sundgot-Borgen (2005) Participation in leanness sports but not training volume is associated with menstrual dysfunction: a national survey of 1276 elite athletes and controls. Br. J. Sports. Med., 39: 141-147.

61. Vanheest J.L., Rodgers C.D., Mahoney C.E., M.J. De Souza (2014) Ovarian suppression impairs sport performance in junior elite female swimmers. Med. Sci. Sports Exerc., 46: 156-166. DOI: 10.129/MSS.0b0143e3182a32672.

62. Williams N.I., H.J. Leidy, B.R. Hill, J.L. Lieberman, R.S. Legro, M.J. De Souza (2015) Magnitude of daily energy deficit predicts frequency but not severity of menstrual disturbances associated with exercise and caloric restriction. Am. J. Physiol. Endocrinol. Metab., 308: E29-E39.

63. Williams N.I., D.L. Helmreich, D.B. Parfitt, A. CastoBalderrama, J.L. Cameron (2001) Evidence of a causal role of low energy availability in the induction of menstrual cycle disturbances during strenuous exercise training. J. Clin. Endocrinol. Metab., 86: 5184-5193.

64. Ziegler P., J.A. Nelson, A Fornell-Barratt., L. Fiveash, A. Drewnowski (2001) Energy and macronutrient intakes of elite figure skaters. J. Am. Diet. Assoc., 101: 319-325.

\section{Received 18.04.2016 \\ Accepted ?.06.2016}

(C) University of Physical Education, Warsaw, Poland 